\title{
Targeted cancer therapy with ribosome biogenesis inhibitors: a real possibility?
}

\author{
Elisa Brighenti ${ }^{1}$, Davide Treré $^{1}$ and Massimo Derenzini ${ }^{1}$ \\ ${ }^{1}$ Department of Experimental, Diagnostic and Specialty Medicine, Bologna University, Bologna, Italy \\ Correspondence to: Massimo Derenzini, email: massimo.derenzini@unibo.it \\ Keywords: cancer chemotherapy, ribosome biogenesis inhibitors, nucleolus, cell cycle, p53 \\ Received: June 29, $2015 \quad$ Accepted: September 04, $2015 \quad$ Published: September 22, 2015
}

This is an open-access article distributed under the terms of the Creative Commons Attribution License, which permits unrestricted use, distribution, and reproduction in any medium, provided the original author and source are credited.

\section{ABSTRACT}

The effects of many chemotherapeutic drugs on ribosome biogenesis have been underestimated for a long time. Indeed, many drugs currently used for cancer treatment - and which are known to either damage DNA or hinder DNA synthesis - have been shown to exert their toxic action mainly by inhibiting rRNA synthesis or maturation. Moreover, there are new drugs that have been proposed recently for cancer chemotherapy, which only hinder ribosome biogenesis without any genotoxic activity. Even though ribosome biogenesis occurs in both normal and cancer cells, whether resting or proliferating, there is evidence that the selective inhibition of ribosome biogenesis may, in some instances, result in a selective damage to neoplastic cells. The higher sensitivity of cancer cells to inhibitors of rRNA synthesis appears to be the consequence of either the loss of the mechanisms controlling the cell cycle progression or the acquisition of activating oncogene and inactivating tumor suppressor gene mutations that up-regulate the ribosome biogenesis rate. This article reviews those cancer cell characteristics on which the selective cancer cell cytotoxicity induced by the inhibitors of ribosome biogenesis is based.

\section{INTRODUCTION}

Many drugs used for treating cancer, such as DNAreactive agents, antimetabolites, and topoisomerase inhibitors, exert their toxic action by damaging DNA or hindering DNA synthesis. The rationale for this chemotherapeutic approach is that DNA integrity and duplication are crucial for proper cellular function and proliferation, respectively. In proliferating normal cells, the damage or inhibition of DNA is sensed by cell-cycle checkpoint factors that block cell cycle progression, thus making it possible for the cell to repair DNA before division (see for review [1-3]). The repair of these lesions is important in preventing apoptotic cell death. In proliferating cancer cells these mechanisms frequently function poorly or not at all $[4,5]$, so DNA damages may more often induce cell death [6]. Therefore, these chemotherapeutic agents may be considered to be more effective against cancer cells than normal proliferating cells. On the other hand, these kinds of drugs, apart from their action on DNA, very frequently also induce an inhibition of ribosome biogenesis [7]. This fact would appear to reduce the specificity of these drugs for cancer cell elimination. In fact, unlike DNA synthesis, the synthesis of rRNA occurs in both proliferating and resting cells, the latter constituting a large portion of normal tissues. However, a series of recent results indicated that - in some instances - a specific, non-genotoxic inhibition of rRNA transcription may result in a selective damage to neoplastic cells (reviewed in [8-12]). Data dealing with the alterations in the relationship between ribosome biogenesis and cell proliferation, as well as with the changes in the mechanisms controlling the ribosome biogenesis rate in cancer cells, may explain the selective cytotoxicity of ribosome biogenesis inhibitors for cancer cells [13-17]. These characteristics - which may be of importance for the selection of an appropriate anticancer therapy on the one hand, and the stimulation of the development of specific rRNA inhibitors on the other - are the subject of this review. For an easier understanding of the topics discussed, a brief description of the main steps in ribosome biogenesis and of its relationship with cell proliferation will be given first. 


\section{Ribosome biogenesis and cell proliferation}

Ribosome biogenesis is the result of a series of coordinated steps that occur in the nucleolus (reviewed in [18-21]). Within the nucleolus, some ribosomal genes are transcribed by RNA polymerase I ( $\mathrm{Pol} \mathrm{I}$ ) to produce the $47 \mathrm{~S}$ rRNA precursor that is then processed in order to generate the mature $18 \mathrm{~S}, 5.8 \mathrm{~S}$, and $28 \mathrm{~S}$ rRNA. The $5 \mathrm{~S}$ rRNA, which is transcribed in the nucleoplasm by RNA Polymerase III (Pol III), is imported to the nucleolus. The assembly of a specific multiprotein complex at the rDNA promoter containing Pol I is necessary for the initiation of $47 \mathrm{~S}$ pre-rRNA synthesis. Within this multiprotein complex, at least three basal factors - the ribosomal DNA transcription factor Rrn3 [22] (also referred to as Transcription Initiation Factor I (TIF-I) A [23]), Selectivity factor 1 (SL1), and Upstream Binding Factor (UBF) - are necessary for ribosome gene transcription in mammals [24].

TFIIIC and TFIIIB transcription factors are necessary for the transcription of the 5S rRNA by Pol III [25-27].The ribosomal proteins (RPs), whose mRNA is transcribed by RNA Polymerase II (Pol II), are also imported to the nucleolus where they assemble with the rRNAs to form both the large pre-60S and the small pre$40 \mathrm{~S}$ incompletely processed subunits of the final mature ribosomal subunits. The large $60 \mathrm{~S}$ subunit contains one each of the 28S, 5.8S, and 5S RNAs, together with 47 ribosomal proteins, called RPLs, whereas the small $40 \mathrm{~S}$ subunit contains only the $18 \mathrm{~S}$ RNA and 32 ribosomal proteins, called RPSs $[28,29]$. The large and small subunits migrate to the cytoplasm, where they make up the final $80 \mathrm{~S}$ ribosome particle. In proliferating cells, the ribosome biogenesis rate appears to be regulated by cell proliferation-controlling processes [30]. During mitosis, Pol I transcription is repressed by the CDK1-cyclin B kinase activity, and re-activation of Pol I transcription at the end of mitosis depends on inhibition of this activity [31-34]. The RNA-polymerase I upstream binding factor (UBF), inactive during mitosis and early G1 phase [35], is phosphorylated by G1-specific cyclin/Cdk complexes thus stimulating rRNA synthesis during G1 phase progression [36]. Phosphorylation of the transcription factor Rrn3/TIFIA and of SL1 also correlate with cell cycle fluctuation of rDNA transcription [24, 37, 38]. Moreover, in cycling cells, the phosphorylation of the $\mathrm{pRb}$ tumor suppressor induced by the cyclin-D-cyclin-dependent protein kinase (CDK)-4, CDK-6 , and cyclin E-CDK-2 complexes during the G1 phase - hinders its binding to UBF and TFIIIB, thus allowing rRNA transcription to increase. In fact, $\mathrm{pRb}$, in its active, non-phosphorylated form, inhibits both rRNA synthesis by binding to UBF [39-42] and Pol III transcription by binding to TFIIIB [43, 44]. Indeed, an up-regulation of the rate of ribosome biogenesis is necessary for the enhanced protein synthesis requested by cells in order to grow in size during the cell cycle phases, thus consequently ensuring the generation of normalsized, viable daughter cells [45]. In this context, it was demonstrated that not so much the capacity of protein synthesis, but rather the production of new ribosomes is important for cell cycle progression [46], a deficiency in ribosome biogenesis activating in fact a p53-dependent checkpoint mechanism [47, 48]. Furthermore, the relationship between ribosome biogenesis rate and cell cycle progression was stressed by the finding that an accelerated or delayed achievement of the appropriate amount of ribosomes during the G1 phase is associated with an accelerated or delayed G1/S-phase progression [49].

\section{The inhibitors of rRNA synthesis induce apoptotic death in cancer cells lacking the p53-pRb control of G1/S phase transition}

During cell cycle progression, there are some active mechanisms that ensure the proper timing of cell cycle events by enforcing the dependence of late events on the completion of early events [50]. These checkpoints exert their function at the G1-S and G2-M phase transitions by arresting cells which, for any reason, should not enter the following phase. Inappropriate ribosome biogenesis appears to be one of these reasons, with perturbed rRNA processing and ribosome assembly inducing cell cycle arrest in a p53-dependent manner [47, 51-56]. There is evidence that any perturbation in ribosome biogenesis causes p53 accumulation and activation. Indeed, in normal conditions, the amount of p53 within the cell is very small due to the fact that $\mathrm{p} 53$ is a short-lived protein that is rapidly degraded by MDM2 (Murine Double Minute 2) and HDM2 in humans, which acts as an E3 ubiquitin ligase facilitating $\mathrm{p} 53$ proteasomal degradation. Ribosome biogenesis perturbation is responsible for the fact that several ribosomal proteins (RPs), no longer used for ribosome construction, may bind to MDM2, thus relieving its inhibitory activity toward p53 which, therefore, accumulates within the cell nucleus (reviewed in [57, 58]). The most important RPs for the inactivation of MDM2 are RPL5 and RPL11 [55, 59-61], which, by forming a complex with the 5S rRNA bind to and inactivate MDM2, all the components of the complex being necessary for the its inhibitory function $[62,63]$. Ribosome biogenesis perturbations block the transition from G1 to S-phase. The mechanism involved in the block of cell cycle progression is activated by $\mathrm{p} 53$ that induces $\mathrm{p} 21$ expression, which in turn - by hindering $\mathrm{pRb}$ phosphorylation - blocks the activity of E2Fs transcription regulators and the consequent transit from $\mathrm{G} 1$ to $\mathrm{S}$ phase $[2,64]$. Thus the activation of the p53-pRb pathway for blocking cell cycle progression in conditions of insufficient ribosome biogenesis is an important mechanism for preventing proliferating cells from dividing without reaching an outfit 
of the cell constituents sufficient for daughter cell survival. Cancer cells are frequently characterized by i) the presence of activating mutations of gene coding for the components of the proliferating and growth factor signaling pathways, ii) the disruption of $\mathrm{pRb}$ function consequent to $\mathrm{RB} 1$ mutation or deletion, overexpression of cyclin D1, cdk4, and cyclin E, and INK4a mutation, gene deletion, or silencing $[65,66]$, and iii) inactivating mutations of p53 $[67,68]$. A frequent effect of these changes is the loss of a normal G1/S phase checkpoint, with the consequent loss of the functional relationship between ribosome biogenesis and cell cycle progression $[13,14]$. What were the consequences of the absence of an efficient G1/S phase checkpoint in proliferating cells upon ribosome biogenesis perturbation? Experimental evidence indicates that, in cells with a normally functioning $\mathrm{p} 53-\mathrm{pRb}$ pathway, the specific inhibition of ribosome biogenesis induced by Actinomycin $\mathrm{D}$ (ActD) treatment at a dose that selectively blocks the Pol I-dependent transcription caused an arrest in cell cycle progression that hindered the cell division with an incomplete ribosome content [13]. When rRNA synthesis was resumed, ribosome biogenesis tended to continue to completion and the cell divided with an appropriate ribosome content, as demonstrated by the absence of quantitative changes in the rRNA content in these cells, even after a $1 \mathrm{~h}$ treatment with ActD every day for four days. In contrast, in the case of cells lacking both p53 and $\mathrm{pRb}$, the exposure to ActD did not influence the cell cycle progression for the absence of the activation of the cellcycle check-points [13], thus leading these cells to divide without having reached an appropriate ribosome content; therefore, the progressive reduction in the ribosome content becomes very quickly incompatible with cell life (Figure 1). In fact, in this case, after ActD treatment a progressively increased cell death rate occurred, due to an increased apoptotic activity, without significant changes in the cell cycle progression rate [13]. The importance of the status of the p53-pRb-mediated control of cell cycle progression in the cell response to chemotherapeutic agents that hinder ribosome biogenesis was also suggested by a study on the effects of 5-Fluorouracyl (5-FU) and methotrexate treatment on human cancer cell lines, after silencing for RB1 expression. In fact, besides the effect on DNA synthesis, a major effect of both drugs is the down-regulation of ribosome biogenesis: 5-FU by inhibiting rRNA processing, and methotrexate by inhibiting rRNA transcription [7]. Therefore, the inhibition of ribosome biogenesis can be considered for a good part responsible for the effects caused by these two drugs in cancer cells. Treatments with 5-FU and methotrexate, at doses and time exposures derived from the evaluation of the interstitial pharmacokinetics of the drugs in vivo [69], caused a marked reduction in the RB1-silenced cancer cell population growth, but not in control cells. Moreover, a higher death rate was observed in drugtreated RB1-silenced cells than in control cells [14]. Therefore, the deficiency of the $\mathrm{pRb}$ and $\mathrm{p} 53$ function, which appeared to give cells an immediate advantage in maintaining proliferation unchanged after ribosome biogenesis inhibition, was on the contrary responsible for the later cell population exhaustion (Figure 1). These observations taken together indicate that the absence of
A

\section{Adequate rRNA synthesis}

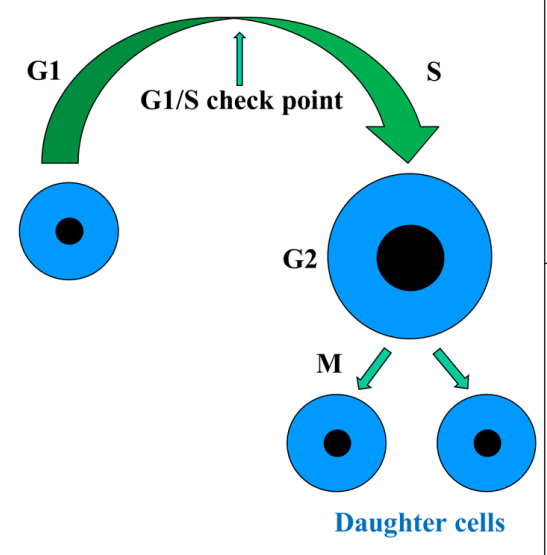

B

\section{Perturbed rRNA synthesis}

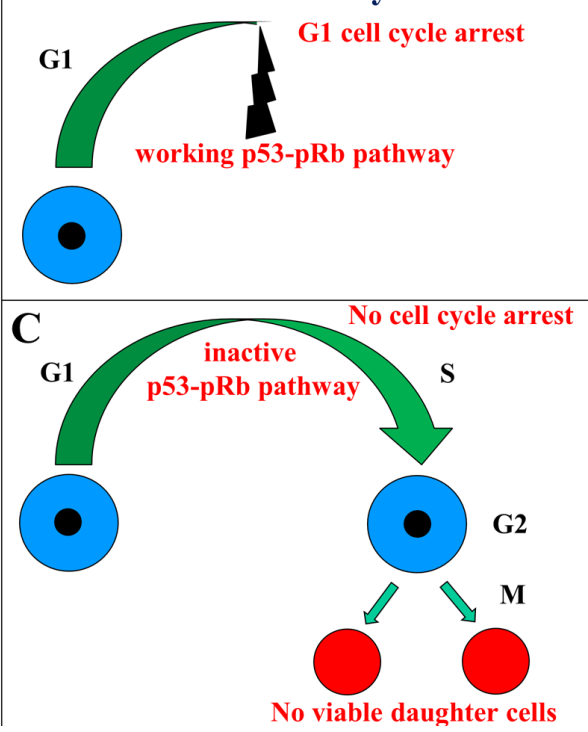

Figure 1: Schematic representation of the relationship between cell cycle progression and ribosome biogenesis. When ribosome biogenesis is adequate, the cell increases in size, passes through the cell cycle phases, and gives rise to two normal daughter cells A. In the case of perturbed ribosome biogenesis, if the p53-pRb pathway normally controls the G1/S phase checkpoint, the cell cycle progression is arrested in the G1 phase $\mathbf{B}$. However, if the p53-pRb pathway is not functioning, the cell cycle progression is not arrested and the cell divides without having reached a sufficient size, thus giving rise to two non-viable daughter cells $\mathbf{C}$. 
the p53-pRb mediated check-point control, as it occur in many cancer cells, may render them more sensitive to the inhibition of ribosome biogenesis than normal cells. In other words, the loss of the two major tumor suppressors is a cancer characteristic that should be exploited in order to selectively eliminate cancer cells by using inhibitors of ribosome biogenesis. In support of this statement are some clinical findings indicating that patients with breast cancers lacking a functioning $\mathrm{p} 53 / \mathrm{pRb}$ pathway and treated with the adjuvant standard chemotherapy regimen, which includes 5-FU and methotrexate, had a more favorable clinical outcome in comparison with patients with cancers with a normally functioning $\mathrm{p} 53 / \mathrm{pRb}$ pathway $[14,15]$.

\section{Ribosome biogenesis has a highly variable rate in cancer cells}

It is a common belief that cancer cells are typically characterized by a higher rate of ribosome biogenesis than the corresponding normal cells. An up-regulated ribosome biogenesis in cancer cells may be considered to be the consequence of the fact that neoplastic transformation is frequently characterized by changes of protooncogenes and tumor suppressor genes [5] which activate mechanisms stimulating cell growth and proliferation, and also trigger a series of pathways which enhance ribosome biogenesis [70]. The extracellular signal-regulated kinase (MAPK/ERK) pathway activates both Pol I transcription, through the phosphorylation of UBF [71, 72], and Pol III transcription, by phosphorylating TFIIIB [21], and ERK phosphorylates the Transcription Initiation Factor TIF-IA which links the initiation-competent Pol I entity with the rDNA promoter [38]. Mitogens and growth factors also activate the PI3K/AKT pathway, which in turn activates MYC [73], the major modulator of ribosome biogenesis. MYC increases Pol I activity by enhancing the recruitment of SL1 to promoters, stimulates ribosomal protein synthesis by increasing Pol II transcription, and facilitates Pol III transcription by activating TFIIIB [27, 74, 75]. Furthermore, the mitogenic growth factor stimulation, through the activation of the mammalian target of rapamycin (mTOR), also induces both Pol I transcription by activating UBF and Rrn3/TIF-IA (the latter not in all cell types), and Pol III transcription by facilitating the association of the transcription factors TFIIIB and TFIIIC with 5S rRNA genes $[18,76]$. Furthermore, there is evidence that the products of the tumor suppressor genes that adversely affect cell proliferation and cell cycle progression also negatively control ribosome biogenesis. In fact, p53 inhibits both Pol I transcription by binding to the selectivity factor SL1 - which is necessary for Pol I recruitment to the rRNA gene promoter [77] - and Pol III transcription by binding to TFIIIB [44]. In the control of ribosome biogenesis, p53 may be aided by p14ARF. In addition to activating the p53 pathway, this tumor suppressor hinders ribosome biogenesis both by inhibiting UBF recruitment on the transcription complex [78], and by down-regulating the activity of nucleophosmin, a multifunctional nucleolar protein involved in rRNA processing [79]. As for the other major tumor suppressor, $\mathrm{pRb}$, it inhibits ribosome biogenesis, as reported above [39-44]. Lastly, Pol I transcription is also repressed by PTEN (phosphatase and tensin homolog deleted in chromosome 10), another important tumor suppressor which activates various signaling events that inhibit cell proliferation and disrupt the SL1 complex [80]. Therefore, the claim that a high activity of ribosome biogenesis characterizes cancer cells appears to be substantiated by the observation that many of the genetic changes occurring in cancer cells up-regulate ribosome biogenesis. On the other hand, there is evidence that the severity of these changes may be highly variable in human cancers, thus giving rise to tumors characterized by a highly variable ribosome biogenesis rate, which is sometimes quite similar to that of the corresponding normal cells [81]. The highly variability of the nucleolar size in cancer cells is long since known $[82,83]$. Of importance from the histopathological standpoint is the fact that the variability in the rate of ribosome biogenesis is reflected in differently-sized nucleoli within cancer cells, the size of the nucleolus being directly related to the rate of ribosome biogenesis $[84,85]$. Accordingly, nucleoli with highly variable size can be observed in histological sections in the same types of cancers, either stained with E\&E (Figures 2A and 2B) or with the silver staining procedure selective for nucleolar visualization (Figures 2C and 2D) (reviewed in [86-88]).

\section{The inhibitors of rRNA synthesis induce apoptotic death in cancer cells with up-regulated ribosome biogenesis}

This high variability in the ribosome biogenesis rate in cancer cells has been found to account for a different sensitivity of cancer cells with functional p53 to the treatment with inhibitors of rRNA synthesis. Recent data indicate that cancer cells exhibiting an upregulated ribosome biogenesis are highly sensitive to drugs inhibiting rRNA transcription or maturation [17]. In fact, it has been shown that the exposure of human cancer cell lines characterized by different levels of rRNA transcription to drugs which inhibit rRNA synthesis induced apoptosis only in the cells with the highest rates of ribosome biogenesis. Moreover, the cancer cells in which the high rRNA synthesis was down-regulated by serum starvation failed to undergo apoptosis after the treatment with rRNA synthesis inhibitors. The induction of apoptosis by ribosome biogenesis inhibitors in cells with high but not with low rRNA synthesis rate was due to the fact that the level of p53 stabilization and of its activity in the activation of the target genes responsible for apoptosis 
induction were directly related to the rRNA synthesis rate of the cells before the drug treatment . Apoptotic cell death is induced only in those cells where a high amount of p53 is stabilized after rRNA synthesis inhibition. This is consistent with previously reported data on the relationship between p53 levels and the induction of apoptosis [89]. Interestingly, the inhibition of rRNA synthesis always stopped the cell cycle, irrespective of the ribosome biogenesis rate of cells. The high and low levels of p53 stabilization induced by rRNA synthesis inhibitors were the consequence of the fact that high and low amounts of ribosomal proteins, no longer used for ribosome building, bind to the ubiquitin ligase MDM2, thus hindering p53 ubiquitylation and proteasomal degradation (Figure 3), according to the well-established RP-MDM2 pathway that controls the cellular level of p53 (see reviews in $[57,58]$ ). The level of p53 stabilization induced by drugs acting in different ways from the inhibition of ribosome biogenesis, such as Hydroxyurea [90], was independent of the level of ribosome biogenesis in cells and lower than that occurring after the inhibition of rRNA synthesis. Worth of note, in cells with a low ribosome biogenesis rate, the combined treatment with Actinomycin D and Hydroxyurea exerted an additive effect on p53 stabilization, thus succeeding in the apoptotic pathway activation even in these cells. The different sensitivity to inhibition of rRNA synthesis depending on a different rate of ribosome biogenesis is very likely at the basis of the preferential induction of apoptosis in tumor cells - when compared to the normal cells of the same lineage - by the selective rRNA synthesis inhibitor CX-5461 [10, 91]. CX-5461, a nongenotoxic drug recently undergoing phase I clinical trials for the treatment of hematologic malignancies, inhibits ribosome biogenesis, most likely by disrupting the SL-1/ rDNA complex [92, 93]. It has been shown that CX-5461 induced p53-dependent apoptosis of malignant B cells, but not of normal cells, in a E $\mu$-MYC mouse model of Burkitt lymphoma, resulting in an increased survival rate of tumor-bearing mice [91]. In these mice, B-lymphocytes constitutively overexpressing MYC are characterized by an enhanced ribosome biogenesis, due to an increased rDNA transcription rates and Pol I machinery abundance [91]. Indeed, MYC controls ribosome biogenesis by stimulating the synthesis of all three DNA-dependent RNA polymerases, thus enhancing the synthesis of $47 \mathrm{~S}$ pre-rRNA, 5S rRNA and ribosomal proteins, which
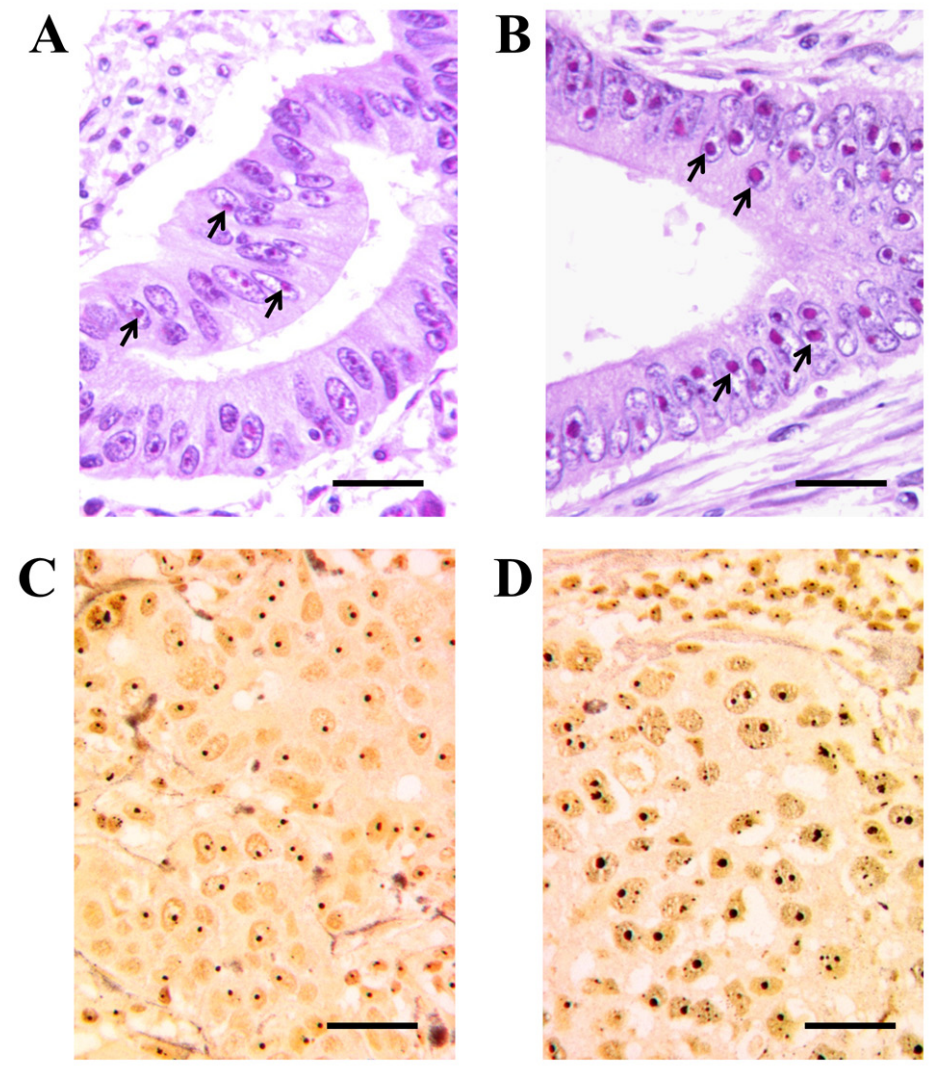

Figure 2: High variability of the nucleolar size in human cancers. A. and B. Histological sections from two routinely processed colon adenocarcinomas stained with hematoxylin and eosin (H\&E). The nucleolus frequently appears as a roundish body mainly stained with eosin, due to its high protein content. Compare the small size of the nucleoli in cancer sample A. with the very enlarged nucleoli in cancer sample B. Both cancers were p53 wild-type. Arrows indicate nucleoli. Bar, $25 \mu \mathrm{m}$. C. and D. Histological sections from two routinely processed infiltrating ductal breast cancers, specifically silver-stained for the argyrophilic nucleolar proteins. Both cancers were p53 wild-type. Nucleoli are very darkly stained by silver. The size of nucleoli in breast cancer sample $\mathbf{C}$. is very small in comparison with that of nucleoli in breast cancer sample D. Bar, $25 \mu \mathrm{m}$. 

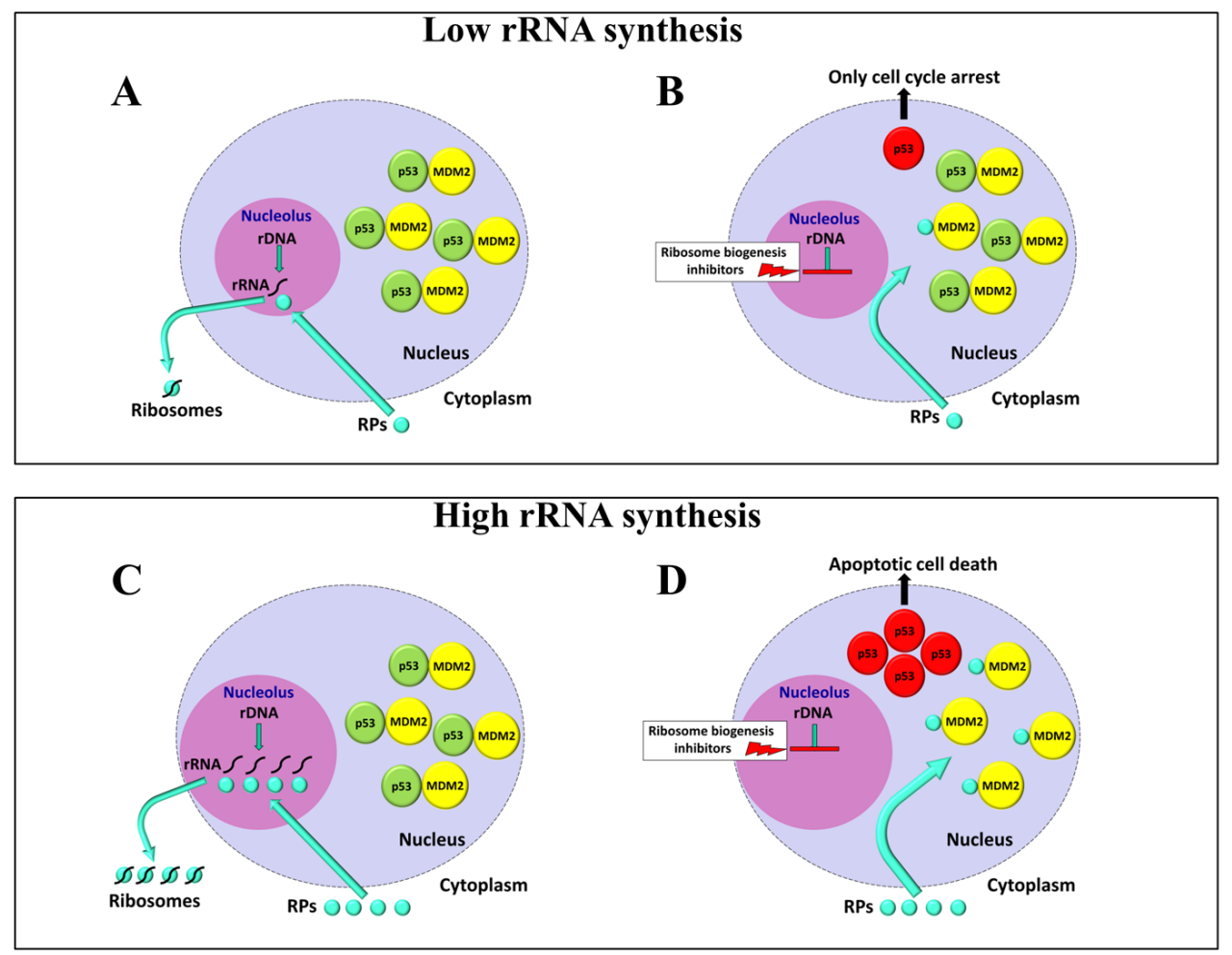

Figure 3: Schematic representation of the effects of ribosome biogenesis inhibitors on cells with different rates of rRNA synthesis. Normally, the nuclear p53 level is very low as a consequence of the fact that newly synthesized p53 is rapidly linked by the oncoprotein MDM2 which mediates the tumour suppressor ubiquitylation and proteasome-dependent degradation. In cells with a low ribosome biogenesis rate, also a low production of ribosomal proteins (RPs) occurs A. In these cells, after the inhibition of ribosome biogenesis, just a few RPs, no longer used for ribosome building, bind to a very few MDM2 molecules, thus only partially neutralizing their ubiquitin ligase activity toward p53, with a consequent induction of a low-level p53 stabilization. A low amount of stabilized p53 is responsible for cell cycle arrest $\mathbf{B}$. In the case of cells characterized by a high ribosome biogenesis rate also a high production of RPs occurs C. The inhibition of rRNA synthesis causes a large number of RPs, no longer used for ribosome building, to bind and neutralize a large number of MDM2 molecules, thus inducing a strong p53 stabilization. A high amount of stabilized p53 is responsible for cell apoptotic death $\mathbf{D}$.

Table 1: Summary diagram of the different efficacy of treatments with inhibitors of ribosome biogenesis in relation to the characteristics of neoplastic cells.

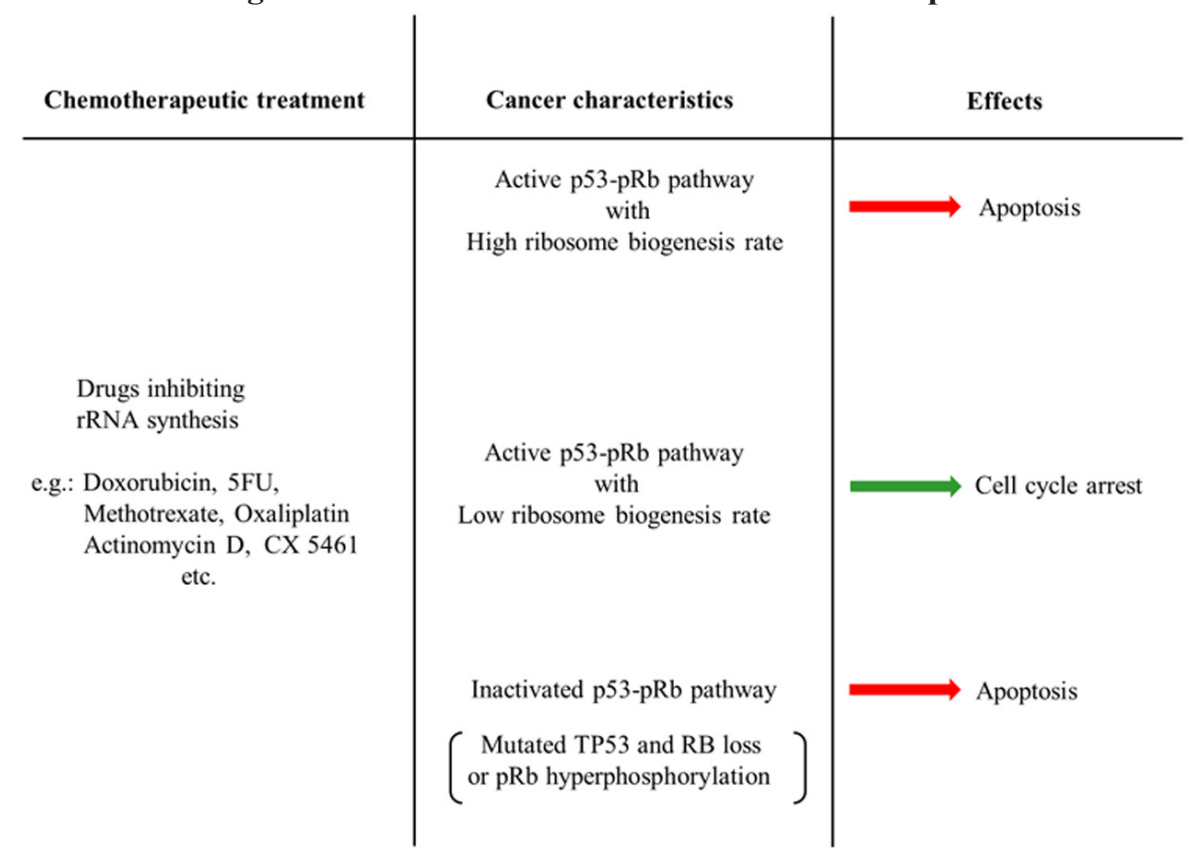


are necessary for ribosome building [94]. That the high sensitivity to CX-5461 was the consequence of the activation of p53 was demonstrated by the fact that E $\mu$ MYC lymphoma cells, with elevated basal rates of Pol I transcription, mutant or null for p53 exhibited a 180fold decreased sensitivity to the drug [91]. On the other hand, the lack of cytotoxic effects in normal cells without up-regulated Pol-1 transcription suggested that the rate of rRNA synthesis of the cells could account for the different sensitivity of cancer cells with functional p53 to the treatment with inhibitors of rRNA synthesis. Therefore, in tumor cells with up-regulated ribosome biogenesis consequent to MYC overexpression, the inhibition of rDNA transcription may well be responsible for a high accumulation and activation of p53, sufficient for the induction of apoptosis, whereas it causes only transient effects in cells with a normally regulated ribosome biogenesis (Figure 3 ).

\section{Future perspectives and conclusions}

The effect of many chemotherapeutic drugs on ribosome biogenesis has been underestimated for a long time. Only recently, it has been shown that the mechanism of action of many drugs used for cancer treatment is mainly based on either the inhibition of rRNA synthesis or maturation [7]. The introduction in cancer chemotherapy of CX-5461, a molecule which selectively hinders Pol I activity without exerting any genotoxic activity, may certainly stimulate more studies aiming to identify and/ or produce compounds that have these characteristics for targeting the nucleolus in cancer cells [95]. In this context, worthy of mention are the recent results obtained using a small molecular compound, BMH-21, and a small-molecule peptide (22mer) which have been found to stabilize p53 by inhibiting rDNA transcription. BMH21 binds to GC-rich sequences and inhibits RNA Pol I activity [96]. It also induces the proteasome-dependent destruction of the large catalytic subunit in the Pol I complex, as do three other small molecular compounds, BMH-9, BMH-22, and BMH-23 [97]. The 22mer targets the interface between RNA polymerase I and Rrn3 thus selectively inhibiting the synthesis of rRNA [98]. Indeed, the development of similar compounds appears to be particularly appropriate, based on the evidence that cancer cells may acquire genetic and metabolic changes that render them much more sensitive to the inhibition of rRNA synthesis than normal cells. Considering the fact that these changes consist of either the loss of the mechanisms controlling the relationship between cell growth and cell cycle progression or an up-regulated ribosome biogenesis, it could be rationally suggested that a pre-treatment analysis should be conducted on cancer samples to define the integrity of their mechanism regulating the G1/S phase checkpoint and to evaluate the rate of ribosome biogenesis. Such a characterization can be carried out very easily and should be very useful for distinguishing those cancers that may benefit greatly from treatment with ribosome biogenesis inhibitors, resulting in apoptosis, from those in which the inhibition of ribosome biogenesis will cause only a cell cycle arrest with a low chemotherapeutic efficacy. A schematic representation of the effects of treatment with inhibitors of ribosome biogenesis in relation to the characteristics of neoplastic cells is shown in Table 1.

\section{ACKNOWLEDGMENTS}

This work was supported by the Roberto and Cornelia Pallotti's Legacy for Cancer Research and Associazione Italiana per la Ricerca sul Cancro (AIRC, grant no. IG13480).

\section{CONFLICTS OF INTEREST}

The authors declare no conflict of interest.

\section{REFERENCES}

1. Zhou BB, Elledge SJ. The DNA damage response: putting checkpoints in perspective. Nature. 2000; 408: 433-439.

2. David-Pfeuty T. The flexible evolutionary anchoragedependent Pardee's restriction point of mammalian cells: how its deregulation may lead to cancer. Biochim Biophys Acta. 2006; 1765: 38-66.

3. Elledge SJ. Cell cycle checkpoints: preventing an identity crisis. Science. 1996; 274: 1664-1672.

4. Sherr CJ. Cancer cell cycles. Science. 1996; 274: 16721677.

5. Sherr CJ. The Pezcoller lecture: cancer cell cycles revisited. Cancer Res. 2000; 60: 3689-3695.

6. Waldman T, Zhang Y, Dillehay L, Yu J, Kinzler K, Vogelstein B, Williams J. Cell-cycle arrest versus cell death in cancer therapy. Nat Med. 1997; 3: 1034-1036.

7. Burger K, Mühl B, Harasim T, Rohrmoser M, Malamoussi A, Orban M, Kellner M, Gruber-Eber A, Kremmer E, Hölzel M, Eick D. Chemotherapeutic drugs inhibit ribosome biogenesis at various levels. J Biol Chem. 2010; 285: 12416-12425.

8. Quin JE, Devlin JR, Cameron D, Hannan KM, Pearson $\mathrm{RB}$, Hannan RD. Targeting the nucleolus for cancer intervention. Biochim Biophys Acta. 2014; 1842: 802-816.

9. Hein N, Hannan KM, George AJ, Sanij E, Hannan RD. The nucleolus: an emerging target for cancer therapy. Trends Mol Med. 2013; 19: 643-654.

10. Poortinga G, Quinn LM, Hannan RD. Targeting RNA polymerase I to treat MYC-driven cancer. Oncogene. 2015; 34: 403-412.

11. Hannan RD, Drygin D, Pearson RB. Targeting RNA polymerase I transcription and the nucleolus for cancer 
therapy. Expert Opin Ther Targets. 2013; 17: 873-878.

12. Bywater MJ, Pearson RB, McArthur GA, Hannan RD. Dysregulation of the basal RNA polymerase transcription apparatus in cancer. Nat Rev Cancer. 2013; 13: 299-314.

13. Montanaro L, Mazzini G, Barbieri S, Vici M, NardiPantoli A, Govoni M, Donati G, Treré D, Derenzini M. Different effects of ribosome biogenesis inhibition on cell proliferation in retinoblastoma protein- and p53-deficient and proficient human osteosarcoma cell lines. Cell Prolif. 2007; 40: 532-549.

14. Derenzini M, Donati G, Mazzini G, Montanaro L, Vici M, Ceccarelli C, Santini D, Taffurelli M, Treré D. Loss of retinoblastoma tumor suppressor protein makes human breast cancer cells more sensitive to antimetabolite exposure. Clin Cancer Res. 2008; 14: 2199-2209.

15. Treré D, Brighenti E, Donati G, Ceccarelli C, Santini D, Taffurelli M, Montanaro L, Derenzini. High prevalence of retinoblastoma protein loss in triple-negative breast cancers and its association with a good prognosis in patients treated with adjuvant chemotherapy. Ann Oncol. 2009; 20: 18181823 .

16. Montanaro L, Treré D, Derenzini M. The emerging role of RNA polymerase I transcription machinery in human malignancy: a clinical perspective. Onco Targets Ther. 2013; 6: 909-916.

17. Scala F, Brighenti E, Govoni M, Imbrogno E, Fornari F, Treré D, Montanaro L, Derenzini M. Direct relationship between the level of p53 stabilization induced by rRNA synthesis-inhibiting drugs and the cell ribosome biogenesis rate. Oncogene. 2015. May 11 [Epub ahead of print] doi: 10.1038/onc.2015.147.

18. Mayer C, Grummt I. Ribosome biogenesis and cell growth: mTOR coordinates transcription by all three classes of nuclear RNA polymerases. Oncogene. 2006; 25: 63846391.

19. Kopp K, Gasiorowski JZ, Chen D, Gilmore R, Norton JT, Wang C, Leary DJ, Chan EK, Dean DA, Huang S. Pol I transcription and pre-rRNA processing are coordinated in a transcription-dependent manner in mammalian cells. Mol Biol Cell. 2007; 18: 394-403.

20. Lempiäinen H, Shore D. Growth control and ribosome biogenesis. Curr Opin Cell Biol. 2009; 21: 855-863.

21. Grummt I. Wisely chosen paths-regulation of rRNA synthesis. FEBS J. 2010; 277: 4626-463.

22. Stepanchick A, Zhi H, Cavanaugh AH, Rothblum K, Schneider DA, Rothblum LI. DNA binding by the ribosomal DNA transcription factor rrn3 is essential for ribosomal DNA transcription. J Biol Chem. 2013; 288: 9135-9144.

23. Bodem J, Dobreva G, Hoffmann-Rohrer U, Iben S, Zentgraf H, Delius H, Vingron M, Grummt I. TIF-IA, the factor mediating growth-dependent control of ribosomal RNA synthesis, is the mammalian homolog of yeast Rrn3p. EMBO Rep. 2000; 1: 171-175.
24. Grummt I. Life on a planet of its own: regulation of RNA polymerase I transcription in the nucleolus. Genes Dev. 2003; 17: 1691-1702.

25. Goodfellow SJ, White RJ. Regulation of RNA polymerase III transcription during mammalian cell growth. Cell Cycle. 2007; 6: 2323-2326.

26. White RJ. RNA polymerase III transcription and cancer. Oncogene. 2004; 23: 3208-3216.

27. White RJ. RNA polymerases I and III, growth control and cancer. Nat Rev Mol Cell Biol. 2005; 6: 69-78.

28. Vladimirov SN, Ivanov AV, Karpova GG, Musolyamov AK, Egorov TA, Thiede B, Wittmann-Liebold B, Otto A. Characterization of the human small ribosomal-subunit proteins by $\mathrm{N}$-terminal and internal sequencing, and mass spectrometry. Eur J Biochem. 1996; 239: 144-149.

29. Odintsova TI, Müller EC, Ivanov AV, Egorov TA, Bienert R, Vladimirov SN, Kostka S, Otto A, WittmannLiebold B, Karpova GG. Characterization and analysis of posttranslational modifications of the human large cytoplasmic ribosomal subunit proteins by mass spectrometry and Edman sequencing. J Protein Chem. 2003; 22: 249-258.

30. Hernandez-Verdun D, Roussel P. Regulators of nucleolar functions. Prog Cell Cycle Res. 2003; 5: 301-308.

31. Sirri V, Roussel P, Hernandez-Verdun D. The mitotically phosphorylated form of the transcription termination factor TTF-1 is associated with the repressed rDNA transcription machinery. J Cell Sci. 1999; 112: 3259-3268.

32. Heix J, Vente A, Voit R, Budde A, Michaelidis TM, Grummt I. Mitotic silencing of human rRNA synthesis: inactivation of the promoter selectivity factor SL1 by cdc2/ cyclin B-mediated phosphorylation. EMBO J. 1998; 17: 7373-7381.

33. Sirri V, Roussel P, Hernandez-Verdun D. In vivo release of mitotic silencing of ribosomal gene transcription does not give rise to precursor ribosomal RNA processing. J Cell Biol. 2000; 148: 259-270.

34. Voit R, Seiler J, Grummt I. Cooperative Action of Cdk1/ cyclin B and SIRT1 Is Required for Mitotic Repression of rRNA Synthesis. PLoS Genet. 2015; 11: e1005246.

35. Klein J, Grummt I. Cell cycle-dependent regulation of RNA polymerase I transcription: the nucleolar transcription factor UBF is inactive in mitosis and early G1. Proc Natl Acad Sci USA. 1999; 96: 6096-6101.

36. Voit R, Hoffmann M, Grummt I. Phosphorylation by G1-specific cdk-cyclin complexes activates the nucleolar transcription factor UBF. EMBO J. 1999; 18: 1891-1899.

37. Blattner C, Jennebach S, Herzog F, Mayer A, Cheung AC, Witte G, Lorenzen K,Hopfner KP, Heck AJ, Aebersold R, Cramer P. Molecular basis of Rrn3-regulated RNA polymerase I initiation and cell growth. Genes Dev. 2011; 25: 2093-2105.

38. Zhao J, Yuan X, Frödin M, Grummt I. ERK-dependent phosphorylation of the transcription initiation factor TIF- 
IA is required for RNA polymerase I transcription and cell growth. Mol Cell. 2003 Feb;11(2):405-13.

39. Cavanaugh AH, Hempel WM, Taylor LJ, Rogalsky V, Todorov G, Rothblum LI. Activity of RNA polymerase I transcription factor UBF blocked by $\mathrm{Rb}$ gene product. Nature. 1995; 374: 177-180.

40. Voit R, Schafer K, Grummt I. Mechanism of repression of RNA polymerase I transcription by the retinoblastoma protein. Mol Cell Biol. 1997; 17: 4230-4237.

41. Hannan KM, Hannan RD, Smith SD, Jefferson LS, Lun $\mathrm{M}$, Rothblum LI. Rb and p130 regulate RNA polymerase I transcription: $\mathrm{Rb}$ disrupts the interaction between UBF and SL-1. Oncogene. 2000; 19: 4988-4999.

42. Ciarmatori S, Scott PH, Sutcliffe JE, McLees A, Alzuherri HM, Dannenberg JH, Te Riele H, Grummt I, Voit R, White RJ. Overlapping functions of the ppRB family in the regulation of rRNA synthesis. Mol Cell Biol. 2001; 21: 5806-5814.

43. White RJ, Trouche D, Martin K, Jackson SP, Kouzarides T. Repression of RNA polymerase III transcription by the retinoblastoma protein. Nature. 1996; 382: 88-90.

44. Felton-Edkins ZA, Kenneth NS, Brown TR, Daly NL, Gomez-Roman N, Grandori C, Eisenman RN, White RJ. Direct regulation of RNA polymerase III transcription by RB, p53 and c-Myc. Cell Cycle. 2003; 2: 181-184.

45. Thomas G. An encore for ribosome biogenesis in the control of cell proliferation. Nat Cell Biol. 2000; 2: E71-E72.

46. Volarevic S, Stewart MJ, Ledermann B, Zilberman F, Terracciano L, Montini E, Grompe M, Kozma SC, Thomas G. Proliferation, but not growth, blocked by conditional deletion of 40S ribosomal protein S6. Science. 2000; 288: 2045-2047.

47. Sulic S, Panic L, Barkic M, Mercep M, Uzelac M, Volarevic S. Inactivation of S6 ribosomal protein gene in $\mathrm{T}$ lymphocytes activates a p53-dependent checkpoint response. Genes Dev. 2005; 19: 3070-3082.

48. Panić L, Montagne J, Cokarić M, Volarević S. S6haploinsufficiency activates the p53 tumor suppressor. Cell Cycle. 2007; 6: 20-24.

49. Derenzini M, Montanaro L, Chillà A, Tosti E, Vici M, Barbieri S, Govoni M, Mazzini G, Treré D. Key role of the achievement of an appropriate ribosomal RNA complement for G1-S phase transition in H4-II-E-C3 rat hepatoma cells. J Cell Physiol. 2005; 202: 483-491.

50. Hartwell LH, Weinert TA. Checkpoints: controls that ensure the order of cell cycle events. Science. 1989; 246: 629-634.

51. Pestov DG, Strezoska Z, Lau LF. Evidence of p53dependent cross-talk between ribosome biogenesis and the cell cycle: effects of nucleolar protein Bop1 on $\mathrm{G}(1) / \mathrm{S}$ transition. Mol Cell Biol. 2001; 21: 4246-4255.

52. Rubbi CP, Milner J. Disruption of the nucleolus mediates stabilization of p53 in response to DNA damage and other stresses. EMBO J. 2003; 22: 6068-6077.
53. Bhat KP, Itahana K, Jin A, Zhang Y. Essential role of ribosomal protein L11 in mediating growth inhibition induced p53 activation. EMBO J. 2004; 23: 2402-2412.

54. Dai MS, Zeng SX, Jin Y, Sun XX, David L, Lu H. Ribosomal protein L23 activates p53 by inhibiting MDM2 function in response to ribosomal perturbation but not to translation inhibition. Mol Cell Biol. 2004; 24: 7654-7668.

55. Lohrum MA, Ludwig RL, Kubbutat MH, Hanlon M, Vousden KH. Regulation of HDM2 activity by the ribosomal protein L11. Cancer Cell. 2003; 3: 577-587.

56. Fumagalli S, Di Cara A, Neb-Gulati A, Natt F, Schwemberger S, Hall J, Babcock GF, Bernardi R, Pandolfi PP, Thomas G. Absence of nucleolar disruption after impairment of 40S ribosome biogenesis reveals an rpL11translation-dependent mechanism of p53 induction. Nat Cell Biol. 2009; 11: 501-508.

57. Zhang Y, Lu H. Signaling to p53: ribosomal proteins find their way. Cancer cell. 2009; 16: 369-377.

58. Deisenroth $\mathrm{C}$, Zhang Y. Ribosome biogenesis surveillance: probing the ribosomal protein-Mdm2-p53 pathway. Oncogene. 2010; 29: 4253-4260.

59. Zhang Y, Wolf GW, Bhat K, Jin A, Allio T, Burkhart WA, Xiong Y. Ribosomal protein L11 negatively regulates oncoprotein MDM2 and mediates p53-dependent ribosomal-stress checkpoint pathway. Mol Cell Biol. 2003; 23: 8902-8912.

60. Dai MS, Lu H. Inhibition of MDM2-mediated p53 ubiquitination and degradation by ribosomal protein L5. J Biol Chem. 2004; 279: 44475-44482.

61. Bursać S, Brdovčak MC, Pfannkuchen M, Orsolić I, Golomb L, Zhu Y, Katz C, Daftuar L, Grabušić K, Vukelić I, Filić V, Oren M, Prives C, Volarevic S. Mutual protection of ribosomal proteins L5 and L11 from degradation is essential for p53 activation upon ribosomal biogenesis stress. Proc Natl Acad Sci U S A. 2012; 109: 20467-20472.

62. Donati G, Peddigari S, Mercer CA, Thomas G. 5S ribosomal RNA is an essential component of a nascent ribosomal precursor complex that regulates the Hdm2-p53 checkpoint. Cell Rep. 2013; 4: 87-98.

63. Sloan KE, Bohnsack MT, Watkins NJ. The 5S RNP couples p53 homeostasis to ribosome biogenesis and nucleolar stress. Cell Rep. 2013; 5: 237-247.

64. Sherr CJ, Roberts JM. CDK inhibitors: positive and negative regulators of G1-phase progression. Genes Dev. 1999; 13: 1501-1512.

65. Sherr CJ, McCormick F. The RB and p53 pathways in cancer. Cancer Cell. 2002; 2: 103-112.

66. Knudsen ES, Knudsen KE. Tailoring to RB. Tumour suppressor status and therapeutic response. Nat Rev Cancer. 2008; 9: 714-724.

67. Harris SL, Levine AJ. The p53 pathway: positive and negative feedback loops. Oncogene. 2005; 24: 2899-2908.

68. Vousden KH, Lu X. Live or let die: the cell's response to p53. Nat Rev Cancer. 2002; 2: 594-604. 
69. Muller M, Bockenheimer J, Zellenberg U. Relationship between in vivo drug exposure of the tumor interstitium and inhibition of tumor cell growth in vitro: a study in breast cancer patients. Breast Cancer Res Treat. 2000; 60: 211217.

70. Kusnadi EP, Hannan KM, Hicks RJ, Hannan RD, Pearson $\mathrm{RB}$, Kang J. Regulation of rDNA transcription in response to growth factors, nutrients and energy. Gene. 2015; 556: 27-34.

71. Stefanovsky V, Langlois F, Gagnon-Kugler T, Rothblum LI, Moss T. Growth factor signaling regulates elongation of RNA polymerase I transcription in mammals via UBF phosphorylation and r-chromatin remodeling. Mol Cell. 2006; 21: 629-639.

72. Stefanovsky VY, Pelletier G, Hannan R, Gagnon-Kugler T, Rothblum RI, Moss T. An immediate response of ribosomal transcription to growth factor stimulation in mammals is mediated by ERK phosphorylation of UBF. Mol Cell. 2001; 8: 1063-1073.

73. Zhu J, Blenis J, Yuan J. Activation of PI3K/Akt and MAPK pathways regulates Myc-mediated transcription by phosphorylating and promoting the degradation of Mad1. Proc Natl Acad Sci U S A. 2008; 105: 6584-6589.

74. Gomez-Roman N, Felton-Edkins ZA, Kenneth NS, Goodfellow SJ, Athineos D, Zhang J, Ramsbottom BA, Innes F, Kantidakis T, Kerr ER, Brodie J, Grandori C. Activation by c-Myc of transcription by RNA polymerases I, II and III. Biochem Soc Symp. 2006; 73: 141-154.

75. van Riggelen J, Yetil A, Felsher DW. MYC as a regulator of ribosome biogenesis and protein synthesis. Nat Rev Cancer. 2010; 4: 301-309.

76. Mayer C, Zhao J, Yuan X, Grummt I. mTOR-dependent activation of the transcription factor TIF-IA links rRNA synthesis to nutrient availability. Genes Dev. 2004; 18: 423434.

77. Zhai W, Comai L. Repression of RNA polymerase I transcription by the tumor suppressor p53. Mol Cell Biol. 2000; 20: 5930-5938.

78. Ayrault O, Andrique L, Fauvin D, Eymin B, Gazzeri S, Seite P. Human tumor suppressor p14ARF negatively regulates rRNA transcription and inhibits UBF1 transcription factor phosphorylation. Oncogene. 2006; 25: 7577-7586.

79. Itahana K, Bhat KP, Jin A, Itahana Y, Hawke D, Kobayashi R, Zhang Y. Tumor suppressor ARF degrades B23, a nucleolar protein involved in ribosome biogenesis and cell proliferation. Mol Cell. 2003; 12: 1151-1164.

80. Zhang C, Comai L, Johnson DL. Expression of PTEN in PTEN-deficient cells represses Pol I transcription by disrupting the SL1 complex. Mol Cell Biol. 2005; 25: 68996911.

81. Derenzini M, Trere D, O'Donohue MF, Ploton D. Interphase nucleolar organizer regions in tumor pathology. Molecular Pathology in Cellular Pathology. Edited by Crocker J, Murray PG. London, Wiley, 2003, pp 138-152.
82. Koller PC. The nucleus of the cancer cell. Exp Cell Res. (Suppl.) 1963; 9: 3-14.

83. Busch H, Smetana K. Nucleoli of tumor cells. The nucleolus. Edited by Busch H and Smetana K. New York, Academic Press, 1970, pp 448-471.

84. Derenzini M, Trerè D, Pession A, Montanaro L, Sirri V, Ochs RL. Nucleolar function and size in cancer cells. Am J Pathol. 1998; 152: 1291-1297.

85. Derenzini M, Trerè D, Pession A, Govoni M, Sirri V, Chieco P. Nucleolar size indicates the rapidity of cell proliferation in cancer tissues. J Pathol. 2000; 191: 181-186.

86. Derenzini M. The AgNORs. Micron. 2000; 31: 117-120.

87. Montanaro L, Treré D, Derenzini M. Nucleolus, ribosomes, and cancer. Am J Pathol. 2008; 173: 301-310.

88. Derenzini M, Montanaro L, Treré D. What the nucleolus says to a tumour pathologist. Histopathology. 2009; 54: 753-762.

89. Chen X, Ko LJ, Jayaraman L, Prives C. p53 levels, functional domains, and DNA damage determine the extent of the apoptotic response of tumor cells. Genes Dev. 1996; 10: 2438-2451.

90. Elledge SJ, Zhou Z, Allen JB. Ribonucleotide reductase: regulation, regulation, regulation. Trends Biochem Sci. 1992; 17: 119-123.

91. Bywater MJ, Poortinga G, Sanij E, Hein N, Peck A, Cullinane C, Wall M, Cluse L, Drygin D, Anderes K, Huser N, Proffitt C, Bliesath J, et al. Inhibition of RNA polymerase I as a therapeutic strategy to promote cancerspecific activation of p53. Cancer Cell. 2012; 22: 51-65.

92. Drygin D, Lin A, Bliesath J, Ho CB, O'Brien SE, Proffitt C, Omori M, Haddach M, Schwaebe MK, Siddiqui-Jain A, Streiner N, Quin JE, Sanij E, et al. Targeting RNA polymerase I with an oral small molecule CX-5461 inhibits ribosomal RNA synthesis and solid tumor growth. Cancer Res. 2011; 71: 1418-1430.

93. Drygin D, Rice WG, Grummt I. The RNA polymerase I transcription machinery: an emerging target for the treatment of cancer. Annu Rev Pharmacol Toxicol. 2010; 50: 131-156.

94. Oskarsson T, Trumpp A. The Myc trilogy: lord of RNA polymerases. Nat Cell Biol. 2005; 7: 215-217

95. Woods SJ, Hannan KM, Pearson RB, Hannan RD. The nucleolus as a fundamental regulator of the p53 response and a new target for cancer therapy. Biochim Biophys Acta. 2014. Nov 11 [Epub ahead of print] pii: S18749399(14)00274-0. doi: 10.1016/j.bbagrm.2014.10.007.

96. Peltonen K, Colis L, Liu H, Trivedi R, Moubarek MS, Moore HM, Bai B, Rudek MA, Bieberich CJ, Laiho M. A targeting modality for destruction of RNA polymerase I that possesses anticancer activity. Cancer Cell. 2014, 25: 77-90.

97. Peltonen K, Colis L, Liu H, Jäämaa S, Zhang Z, Af Hällström T, Moore HM, Sirajuddin P, Laiho M. Small Molecule BMH-Compounds That Inhibit RNA Polymerase I and Cause Nucleolar Stress. Mol Cancer Ther. 2014; 13: 
$2537-2546$

98. Rothblum K, Hu Q, Penrod Y, Rothblum LI. Selective inhibition of rDNA transcription by a small-molecule peptide that targets the interface between RNA polymerase I and Rrn3. Mol Cancer Res. 2014; 12: 1586-1596. 